\title{
Mass Screening of the Newborn for Metabolic Disease
}

Over large parts of the world all newborn infants are, in principle or in practice, examined by some biochemical technique for phenylketonuria. This revolutionary practice is barely 10 years old; it is worth considering how it started and why it has spread.

Until the development of a dietary treatment, phenylketonuria was considered, like the other inborn errors of metabolism, a suitable subject for academic research but of no importance to the practising paediatrician. This changed when it was found that dietary treatment of affected children aged more than a few months often led to improvement in their neurological and other signs and symptoms. However, some irreversible damage to the brain occurred during those first months-for optimum effect, treatment had to start within a few weeks of birth, long before any symptoms appeared (Woolf et al., 1958). Diagnosis had therefore to depend on biochemical tests of blood or urine from apparently well babies; and logically, such tests would have to be applied to all newborn infants. Preventive medicine of this type marks a revolution in medical thought; like all revolutions, it is not entirely unopposed, nor is it bloodless.

The principle of screening all newborn infants for phenylketonuria has been very widely, though not quite universally, accepted-the major problems have been in obtaining the necessary specimens and in the tests themselves. The first attempt at mass screening all newborn infants in a city used liquid urine specimens collected by the mothers; the difficulties in obtaining suitable specimens of urine caused only $25 \%$ of newborn infants to be tested (Gibbs and Woolf, 1959). Use of 'Phenistix' by the health visitor improved the test rate to over $99 \%$, but difficulties arose in carrying out and interpreting the test and in the later discovery of 'occult' phenylketonurics who gave negative results with Phenistix (Woolf, 1967a). For these and other reasons a considerable proportion of infants with phenylketonuria (perhaps $40 \%$ ) were not diagnosed when Phenistix was nominally being widely used (Pitt and Wilmot, 1964; Stephenson and
McBean, 1967; Woolf, 1967b; Carson, Carré, and Neill, 1968).

Much more reliable laboratory tests are now available, e.g. the Guthrie inhibition assay using blood (Guthrie and Susi, 1963), spectrofluorometric assay of phenylalanine in blood (Hill et al., 1965; Searle et al., 1967), paper chromatographic detection of $o$-hydroxyphenylacetic acid in urine (Berry Umbarger, and Sutherland, 1965; Woolf, 1967a) or of phenylalanine in blood (Berry, 1962; Efron et al., 1964; Scriver, Davies, and Cullen, 1964; Mellon and Stiven, 1966). The blood specimens are collected by heel-prick on absorbent paper or in heparinized capillary tubes, the urine specimens by the mother placing absorbent paper in the infant's napkin. In Cardiff, for example, $98.9 \%$ of the infants born during 1967 were screened for phenylketonuria and six other inborn errors of metabolism by chromatographic examination of urine collected on filter paper. The chromatographic test for urinary $o$-hydroxyphenylacetic acid usually becomes positive at the same time as the Guthrie test on blood, on day 2-5 or occasionally later, and comparative tests have shown that the two are equally reliable: urine collection on or after day 10 to 14 is recommended for administrative and other reasons (Woolf, 1967a; and unpublished). Tests for urinary phenylpyruvic acid, in contrast, may not become positive for weeks, if at all. Testing filter paper urine specimens with ferric chloride overcomes the difficulties and uncertainties of collecting liquid specimens or using Phenistix on a wet napkin; however, a phenylketonuric might not give a positive result till he was 6 weeks old and, if he were of the occult type, not even then. Furthermore, phenylpyruvic acid gradually decomposes on filter paper (Centerwall, Berry, and Woolf, 1963), and a proportion of false negative results is to be expected from this cause.

In this issue Cahalane (1968) reports the use of the Guthrie method in Ireland. The great bulk of the specimens of blood were collected, before discharge, in the hospitals in which the babies were born. Administratively this is by far the simplest 
and cheapest time and place to collect blood, but there are some disadvantages. In phenylketonuria, the concentration of phenylalanine in the blood is normal at birth and rises to 'positive' levels during the course of a few days. Discharge home normally occurs at ages varying from 2 to 7 days in different hospitals. Most of Cahalane's specimens were apparently collected at 3 to 4 days, an age when between 80 and $90 \%$ of phenylketonurics give a positive result (R. Guthrie, 1966, personal communication). Postponing the test till the age of 6 days or later might have raised the reliability to nearly $100 \%$, but most of the infants would have left hospital and the problem of obtaining specimens would have taken on new dimensions. In screening $72 \%$ of the newborn population of Ireland, Cahalane has ensured that at least $90 \%$ of the phenylketonurics among those tested are detected early enough for treatment to be fully effective. To raise these figures might require collection of blood outside the maternity hospitals, presumably by the G.P., local authority doctor, health visitor, or midwife. This problem occurs in all test procedures using blood, but urine can be collected at home by the mother, using filter paper in the napkin, and can be sent to the laboratory by post; however, in some cases it is easier to collect a blood specimen.

The economics of mass screening must be considered. The alternative to detecting and treating phenylketonuria is, in all probability, profound mental retardation. Phenylketonurics are not especially shortlived, and the cost to society, whether the affected individual is institutionalized or looked after at home, far outweighs the cost of the screening programme necessary to detect him and of his treatment. It is no accident that mass screening has been adopted by some of the less wealthy countries; they can least afford not to screen. On the laboratory side, Cahalane has shown that one technician using the Guthrie method and one parttime secretary can cover all births in Ireland. All the other laboratory techniques for mass screening for phenylketonuria are similarly economical of skilled manpower, materials, and laboratory space. Low running costs are, of course, a prerequisite of any mass screening programme. It is universally accepted that testing must be carried out in centralized laboratories; only in this way can running costs be kept down and enough experience gained to make the tests reliable. The provision of one laboratory covering 50,000 to 100,000 births a year would seem close to the ideal, though geographical factors also enter.

For the technician, the very simplicity and speed of the laboratory procedures can be a drawback; carrying out many thousands of repetitive tests is extremely monotonous, particularly as only one positive result is found for several thousand negative ones. Automation is necessary; of the various techniques available, the spectrophotofluorometric method is at present the one most easily adapted to automation, but other methods have also been automated, though present equipment may soon be outdated.

Collecting the specimens is often more difficult and, in real terms, more costly than the laboratory procedures. The success or failure of any mass screening programme depends on specimen collection. In Great Britain it is possible for a midwife or health visitor to visit every newborn infant in its home at the optimum time and collect a specimen of blood or explain to the mother how to obtain a urine specimen. This is not true everywhere, and it may be necessary to compromise by obtaining specimens at a less reliable age, before leaving maternity hospital, and so test a higher proportion of the newborn population. A second test can be carried out after a few weeks but this more than doubles the cost.

The prevalence of phenylketonuria differs in different populations, even within the British Isles (Carter and Woolf, 1961); this must have a bearing on the choice of testing procedure. Cahalane found 14 phenylketonurics in 62,856 newborn, a prevalence of 1 in 4490, in reasonable agreement with the calculated value (Woolf and Goodwin, 1967); so high a prevalence would seem to justify considerable expenditure in extending and perfecting the screening, e.g. by testing at 6 days or later or by retesting every baby at 3 or 4 weeks of age, not necessarily by the same technique. Elsewhere, with a lower prevalence, it may be more economical to test less thoroughly, e.g. only in maternity hospitals if the prevalence is low enough, and screening for phenylketonuria is probably not justifiable at all in some African countries where the frequency of the phenylketonuria gene is very low.

In the U.S.A., 37 states have passed laws requiring that screening tests should be available for newborn infants. The propriety of such legislation has been questioned (Bessman, 1966, 1967a, b; Cooper, 1967; Hsia, 1967). Screening programmes in the U.S.A. have detected 203 phenylketonurics in 2,205,006 Guthrie tests, a prevalence of 1 in 10,862 (Guthrie, personal communication). Earlier, ascertainment among the mentally retarded had indicated a prevalence of about 1 in 20,000, a figure close to that accepted for England and Wales. Phenylketonurics are not particularly prone to die in infancy, and it seems from these figures that one 
out of every two infants detected by the Guthrie test would, if untreated, either not develop mental retardation or not give a positive reaction for phenylketonuria in later life. This numerical discrepancy has been seized on by critics of mass screening who suggest that the apparent success of dietary treatment may result from the selection of infants who would in any case have been mentally normal (Bessman, 1966). The latest data available seem to disprove this contention and to show that a low-phenylalanine diet is truly efficacious in preventing or minimizing mental retardation in phenylketonuria (Hsia, 1967; Fuller, 1967). Bessman's criticisms of mass screening, the mode of treatment, and the assessment of results have, however, been extremely valuable in stimulating fresh thought and work on phenylketonuria. There was a danger of complacency in our attitudes; Professor Bessman has removed this and shown how much remains to be discovered about this disease.

The difference between the numbers of phenylketonurics ascertained through mental deficiency institutions and by screening the newborn is largely, but not entirely, explained by the finding of transient hyperphenylalaninaemia of various types (Hsia, 1967; Scriver, 1967; MacCready, 1967; Kennedy, 1967). One type can lead to mental retardation, if untreated, but most of the affected individuals would, in later life, give negative results in some tests for phenylketonuria (Justice, O'Flynn, and Hsia, 1967; MacCready, 1967; Stephenson and McBean, 1967). This type of hyperphenylalaninaemia can best be distinguished from phenylketonuria by watching the infant's phenylalanine requirements or by a phenylalanine tolerance test, in either case after a few months on a low-phenylalanine diet. More transient, and probably harmless, forms of hyperphenylalaninaemia occur, in Cahalane's series in nearly $0.1 \%$ of the population screened, outnumbering the phenylketonurics by 3 or 4 to 1 . Any mass screening procedure must, of course, be regarded as a means of selecting individuals for diagnostic tests, rather than as a diagnostic test in its own right, and up to $2 \%$ of false positive results may be acceptable.

Phenylketonuria is only one of a number of inborn errors of metabolism that can be treated with an appropriate diet from early infancy, thus preventing the worst of the clinical consequences. It is an accident of history that phenylketonuria has received so much attention and the other conditions have been largely neglected. It is possible, with very little additional expense, to test for other conditions the blood or urine specimens collected for screening for phenylketonuria. The various chromatographic methods are particularly suitable for this: the urine test used in Oxford will detect tyrosinosis, histidinaemia, homocystinuria, cystinuria, galactosaemia, and renal tubular dysfunction, as well as phenylketonuria (Woolf, 1967a); the blood chromatography technique will detect maple syrup urine disease, homocystinuria, hyperglycinaemia, hyperprolinaemia, hydroxyprolinaemia, and, somewhat less reliably, tyrosinosis and histidinaemia. A modified Guthrie inhibition assay is being used in Massachusetts to detect maple syrup urine disease and galactosaemia (MacCready, 1967); a further modification under development may permit the detection of 19 different diseases (R. Guthrie, 1966, personal communication). The need for speed in diagnosis and early treatment is especially acute in galactosaemia and maple syrup urine disease where a very few days can mean the difference between life and death. Galactosaemia can be detected by examining cord blood by the technique of Beutler, Baluda, and Donnell (1964). Although this would necessitate an independent screening programme, it would be so easy and cheap to obtain specimens, at least from hospital deliveries, that if an automated form of the test were developed its adoption should be seriously considered. In appropriate geographical regions, cord blood could also be screened for deficiency of glucose-6-phosphate dehydrogenase, the cause of favism etc.

In the British Isles as a whole, mass screening of the newborn for phenylketonuria is plainly worth while from the standpoints of the economist, the paediatrician, and, most of all, the affected children and their parents. The same is probably true of homocystinuria, histidinaemia, tyrosinosis, and, more doubtfully, galactosaemia. For maple syrup urine disease it may be only the paediatrician, the affected child, and the parents who consider this kind of preventive medicine worth while-to screen the newborn population for so rare a disease cannot be defended on purely economic grounds unless the costs can be absorbed elsewhere. This raises moral and ethical problems which society will have to solve.

\section{I. WOOLF`}

Member of External Staff, Medical Research Council, Department of the Regius Professor of Medicine, Radcliffe Infirmary, Oxford.

* Present address: Division of Neurological Sciences, Department of Psychiatry, University of British Columbia, Vancouver 8, British Columbia, Canada. 


\section{REFERFNCES}

Berry, H. K. (1962). Use of micromethod for phenylalanine in management of phenylketonuric patients. Clin. Chem., 8, 172. -, Umbarger, B., and Sutherland, B. S. (1965). Procedures for monitoring the low-phenylalanine diet in treatment of phenylketonuria. F. Pediat., 67, 609.

Bessman, S. P. (1966). Legislation and advances in medical knowledge-acceleration or inhibition? ibid., 69, 334.

- (1967a). Legislation and advances in knowledge-acceleration or inhibition? (Letter to the Editor.) ibid., 70, 152.

- (1967b). The implications of the drive for screening. In Phenylketonuria and Allied Metabolic Diseases, p. 177. Ed. by J. A. Anderson and K. F. Swaiman. U.S. Department of Health, Education, and Welfare, Children's Bureau, Washington.

Beutler, E., Baluda, M., and Donnell, G. N. (1964). A new method for the detection of galactosemia and its carrier state. F. Lab. clin. Med., 64, 694.

Cahalane, S. F. (1968). Phenylketonuria: mass screening of newborns in Ireland. Arch. Dis. Childh., 43, 141.

Carson, N. A. J., Carré, J. J., and Neill, D. W. (1968). Results of routine screening for phenylketonuria in early infancy. Northern Ireland (1960-67). ibid., 43, 145.

Carter, C. O., and Woolf, L. I. (1961). The birthplaces of parents and grandparents of a series of patients with phenylketonuria in south-east England. Ann. hum. Genet., 25, 57.

Centerwall, W. R., Berry, H. K., and Woolf, L. I. (1963), Detection. In Phenylketonuria, p. 114. Ed. by F. L. Lyman. C. C. Thomas, Springfield, Illinois.

Cooper, J. D. (1967). The role of government and legislation in management of problems in medicine. In Phenylketonuria and Allied Metabolic Diseases, p. 168. Ed. by J. A. Anderson and K. F. Swaiman. U.S. Department of Health, Education, and Welfare, Children's Bureau, Washington.

Efron, M. L., Young, D., Moser, H. W., and MacCready, R. A. (1964). A simple chromatographic screening test for the detection of disorders of amino acid metabolism. New Engl. 7. Med., 270, 1378.

Fuller, R. (1967). Phenylketonuria: psychological and developmental evaluation. In Phenvlketonuria and Allied Metabolic Diseases, p. 133. Ed. by J. A. Anderson and K. F. Swaiman. U.S. Department of Health, Education, and Welfare, Children's Bureau, Washington.

Gibbs, N. K., and Woolf, L. I. (1959). Tests for phenylketonuria. Results of a one-year programme for its detection in infancy and among mental defectives. Brit. med. $\mathcal{J}$., 2, 532.
Guthrie, R., and Susi, A. (1963). A simple phenylalanine method for detecting phenylketonuria in large populations of newborn infants. Pediatrics, 32, 338.

Hill, J. B., Summer, G. K., Pender, M. W., and Roszel, N.O. (1965). An automated procedure for blood phenylalanine. Clin. Chem., $11,541$.

Hsia, D. Y.-Y. (1967). Phenylketonuria 1967. Develop. Med. Child Neurol., 9, 531.

Justice, P., O'Flynn, M. E., and Hsia, D. Y.-Y. (1967). Phenylalanine-hydroxylase activity in hyperphenylalaninaemia. Lancet, $1,928$.

Kennedy, J. L., Jr. (1967). Discussion. In Phenylketonuria and Allied Metabolic Diseases, p. 162. Ed. by J. A. Anderson and K. F. Swaiman. U.S. Department of Health, Education, and Welfare, Children's Bureau, Washington.

MacCready, R. A. (1967). Public Health laboratory screening programs. ibid., p. 157.

Mellon, J. P., and Stiven, A. G. (1966). A rapid method for the detection of plasma phenylalanine. F. med. Lab. Technol., 23, 204

Pitt, D., and Wilmot, A. E. (1964). Phenylketonuria in Victoria. In Proceedings of the 3rd International Congress on the Scientific Study of Mental Retardation, Copenhagen, 1964, Vol. 2, p. 502. Ed. by J. Øster. Copenhagen.

Scriver, C. R. (1967). Diagnosis and treatment: interpreting the pcsitive screening test in the newborn infant. Pediatrics, 39 , 764

-, Davies, E., and Cullen, A. M. (1964). Application of a simple micromethod to the screening of plasma for a variety of aminoacidopathies. Lancet, 2, 230.

Searle, B., Miiuskovic, M. B., Widelock, D., and Davidow, B. (1967). A manual fluorometric paper disc method for detecting phenylketonuria. Clin. Chem., 13, 621.

Stephenson, J. B. P., and McBean, M. S. (1967). Diagnosis of phenylketonuria (phenylalanine hydroxylase deficiency, temporary and permanent). Brit. med. F., 3, 579 .

Woolf, L. I. (1967a). Large scale screening for metabolic disease in the newborn in Great Britain. In Phenvlketonuria and Allied Metabolic Diseases, p. 50. Ed. by J. A. Anderson and K. F. Swaiman. U.S. Department of Health, Education, and Welfare, Children's Bureau, Washington.

- - (1967b). Phenylketonuria: a reassessment of screening by napkin test. Brit. med. F., 3, 862.

, and Goodwin, B. L. (1967). Effect of dietary treatment on frequency of phenylketonuria gene. Lancet, 1, 216

-, Griffiths, R., Moncrieff, A., Coates, S., and Dillistone, F. (1958). The dietary treatment of phenylketonuria. Arch. Dis. Childh., 33, 31. 